\title{
Analysis of Seasonal Energy Characteristics of the Marmara Sea Upper Layer Dynamics
}

\author{
S. G. Demyshev, S. V. Dovgaya ${ }^{\square}$ \\ Marine Hydrophysical Institute of RAS, Sevastopol, Russian Federation \\ \ovgayasvetlana0309@yandex.ru
}

Purpose. The aim of the work is to assess the role of the basic forces in formation of the dynamic structures of the upper layer in the Marmara Sea in different hydrological seasons.

Methods and Results. The numerical model developed in Marine Hydrophysical Institute, Russian Academy of Sciences, was used to calculate the hydrodynamic and energy characteristics of the sea circulation. The horizontal spatial resolution was $1.22 \times 0.83 \mathrm{~km}, 18$ horizons were used vertically, and the time step was $0.5 \mathrm{~min}$. The characteristics of the waters inflowing through the Bosporus and Dardanelles straits corresponded to the available observational data. On the sea surface, the daily average fields of tangential wind stress, heat fluxes, precipitation and evaporation for 2008 were preset; these parameters were calculated using the regional atmospheric model MM5. Spatial distributions of the vortex structures and the corresponding energy flows in the upper sea layer for different seasons were considered. Having been analyzed, the average seasonal spatial distributions of the current velocity fields and the components of the kinetic energy budget showed that during the year, the vortices in the upper sea layer were formed mainly by two mechanisms. In the central part of the sea, generation of a large-scale anticyclone and its seasonal variability are basically conditioned by the wind forcing, whereas formation and evolution of coastal cyclonic eddies are caused by the buoyancy force. In the fields where the buoyancy, pressure and friction forcing takes place, the zones of local extremes are distinguished. Two of them are the areas of water inflow through the Bosphorus and Dardanelles straits. The strongest variability is observed in the Bosporus region that is certainly conditioned by the fact that the inflowing Black Sea waters have a decisive influence on seasonal nature of the Marmara Sea circulation. The extreme values in the other zones are the result of the coastline structure heterogeneities, that leads to formation of the coastal eddies, the energy source for which is the available potential energy.

Conclusions. Analysis of the results of the performed numerical experiment makes it possible to conclude that in the upper layer of the Marmara Sea, formation and variability of the central anticyclone are conditioned by the wind forcing, while those of the coastal cyclones - by the buoyancy effect.

Keywords: numerical hydrodynamic model, Marmara Sea, anticyclone, cyclone, kinetic energy, wind forcing, buoyancy forcing

Acknowledgments: the investigation was carried out within the framework of the state task on theme № 0555-2021-0004 "Fundamental studies of oceanological processes determining state and evolution of marine environment under the influence of natural and anthropogenic factors, based on observation and modeling methods".

For citation: Demyshev, S.G. and Dovgaya, S.V., 2021. Analysis of Seasonal Energy Characteristics of the Marmara Sea Upper Layer Dynamics. Physical Oceanography, [e-journal] 28(5), pp. 471-485. doi:10.22449/1573-160X-2021-5-471-485

DOI: 10.22449/1573-160X-2021-5-471-485

(c) S. G. Demyshev, S. V. Dovgaya, 2021

(C) Physical Oceanography, 2021

\section{Introduction}

The dynamics of the waters of the Black and Aegean Seas is significantly influenced by the Marmara Sea, which is a part of the water connecting system 
between them. The first results on numerical modeling of vertical hydrodynamic processes in the Marmara Sea using a simplified box model are given in [1].

Using a numerical nonlinear three-dimensional model of Marine Hydrophysical Institute (MHI) in [2], the characteristic features of the dynamics of the basin waters under effect of flows of the impulse through the Bosphorus and Dardanelles straits and without taking into account the effect of atmospheric flows were calculated. A series of the sea circulation features have been obtained, namely: the formation of $S$-shaped jet stream directed from the Bosphorus to the Dardanelles in the sea upper layer, with the maximum velocities of up to $60 \mathrm{~cm} / \mathrm{s}$, periodic formation near the northern boundary of a cyclonic vortex. Numerical solutions that reproduce the general circulation in the sea in September - December 2008 and February - March 2009 using the ROMS model and real experimental data are presented in [3]. It is shown that the wind and water flows through the straits affect the strength and location of the main mesoscale features of the sea circulation.

The hydrophysical fields of the waters of the Marmara Sea for September and December 2013 in [4] were constructed on the basis of the method of the multicomponent splitting for a modified model with artificial compressibility for solving three-dimensional equations of ocean hydrodynamics without the hydrostatic approximation. It is indicated that the effects of non-hydrostatic dynamics are manifested on the bottom slopes, where the current intensifies and its temporal variability is manifested.

Using the general circulation model of the Massachusetts Institute of Technology (MITgcm), the work [5] studies a mixed baroclinic-barotropic response in the Turkish Strait System (TSS), including the Bosphorus, the Marmara Sea and the Dardanelles, in the absence of atmospheric and tidal effects. The types of water circulation in the sea surface layer have been obtained for a two-layer exchange through the Bosphorus Strait and for blocking the flow through its lower layer.

Numerical modeling of the Marmara Sea circulation as part of the Azov Black - Marmara - Mediterranean Seas cascade system using a model with an unstructured SCHISM grid was carried out in [6]. Correlation analysis of the numerical results showed that the transfer process between the Black and Marmara Seas is influenced not only by the difference in the sea levels on the both sides of the Bosphorus, but also by the circulation characteristics of these seas, which make a significant contribution to the water transport in this region.

In the work [7], for 2008-2013 period the circulation in the TSS was simulated using an unstructured grid under real atmospheric forcing. It was found that, depending on the maximum wind stress localization, two different average annual types of circulation of the Marmara Sea surface waters arise. When the maximum wind stress is localized in the central basin, the Bosporus jet flows southward and turns westward after reaching the Bozburun Peninsula. On the contrary, when the area of the maximum wind stress increases and expands in the north - south direction, the jet deviates to the west and, reaching the southern coast, forms a cyclonic gyre in the central basin.

An experiment on modeling of the OSSE (Observing System Simulation Experiment) in the considered basin is presented in [8]. The work uses a highresolution ocean circulation model (FESOM) with the data assimilation of the observational ensemble (DART) along the route of passenger ferries in the Marmara 
Sea eastern part. The results of the work show that the use of measurement data along the route of ferry traffic can significantly reduce the errors in determining the salinity and temperature fields in the upper layer of the sea. The influence of data assimilation on the description of processes in the lower layer is insignificant due to strong stratification.

In order to understand the physical causes for the formation of hydrodynamic features of circulation in sea basins, including the Marmara Sea, an analysis of the energy balance is important. It allows one to assess the role of the main forces in the formation and evolution of currents and density field. In [9], discrete equations for change rate of kinetic and potential energy that correspond to the finite-difference equations of MHI numerical hydrodynamic model were received, and the features of the climatic circulation energy cycles of the Black Sea waters were studied. This paper studies the spatial distributions of energy characteristics of the water dynamics in the Marmara Sea upper layer for 2008 and the role of the main forces in the formation and evolution of eddy structures of various spatial-temporal scales.

\section{Model parameters}

The topographic peculiarities of the Marmara Sea basin are represented in Fig. 1. The system of equations of the Marmara Sea model in the Boussinesq approximations, hydrostatics and sea water incompressibility and the applied parameters are given in $[10,11]$. Now we recall the values of these parameters: the calculation was carried out at 18 horizons by vertical; $1.22 \mathrm{~km}$ and $0.83 \mathrm{~km}$ are the model resolution along $x$ and $y$ axes, respectively; $0.5 \mathrm{~min}$ is a time step. In the Bosphorus Strait, the flow velocities were calculated from the discharges in the upper layer equal to $650 \mathrm{~km}^{3} /$ year, in the lower layer - $350 \mathrm{~km}^{3} /$ year. In order to calculate current velocities in the Dardanelles Strait, the flow velocities 830 and $530 \mathrm{~km}^{3} /$ year, respectively were used [1, 12]. According to [13], the water coming from the Bosphorus Strait had a temperature that varied with depth and time within the range of $8-23.5^{\circ} \mathrm{C}$, the salinity varied from 21 to $30 \%$ depending on the depth. Water masses inflowing through the Dardanelles Strait had $14.6{ }^{\circ} \mathrm{C}$ temperature, salinity varied along the horizons from 34.5 to $38.68 \%$ $[14,15]$.

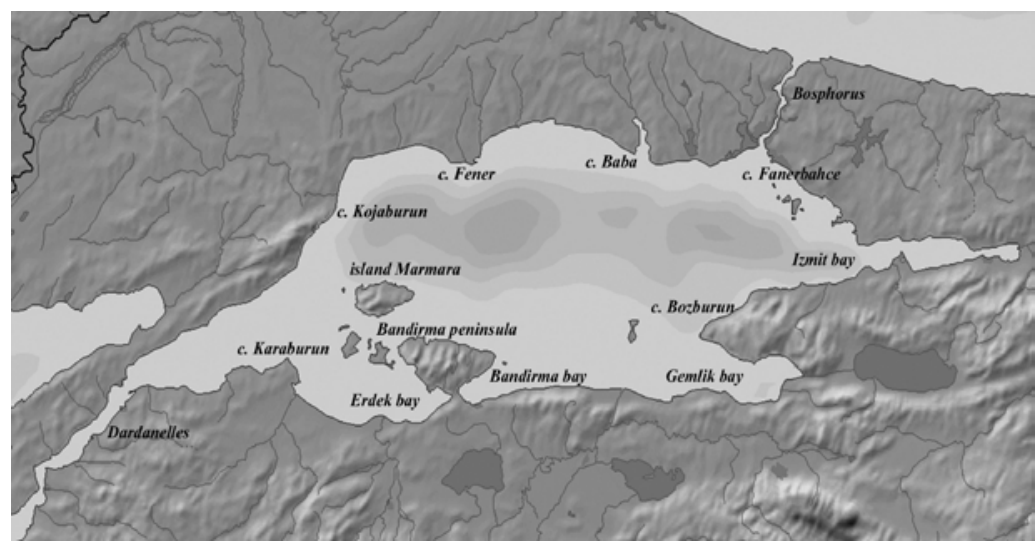

F i g. 1. Schematic topographic map of the Marmara Sea basin 
The calculation results for the regional atmospheric model Fifth-Generation Penn State/NCAR Mesoscale Model version 3.7 (MM5) (URL: http://www.ucar.edu/mm5/mm4/home.html) were used for definition the average daily fields of tangential wind stress friction, heat fluxes, precipitation and evaporation on the sea surface for 2008.

As the initial fields for level, temperature, salinity, current velocity horizontal components, we took the fields obtained as a result of a numerical calculation using the same model with similar parameters, but without taking into account the influence of the atmosphere [2] and corresponded to August $28\left(6620^{\text {th }}\right.$ day of counting).

\section{Analysis of numerical experiment results}

We consider the spatial distributions of eddy structures and the corresponding energy fluxes in the sea upper layer for different seasons. Winter, spring, summer and autumn hydrological seasons are the three-month intervals starting from January 1, April 1, July 1 and October 1, respectively.

In differential form, we recall the represent of the equation for the change rate of kinetic energy (KE) and its components [11]. Since in the quasi-static approximation $\mathrm{KE}$ is expressed in the form $E=\rho_{0}\left(u^{2}+v^{2}\right) / 2$, the symbolic representation of $\mathrm{KE}$ budget equation will be as follows

$$
E_{t}+A d v(P+E)=B F W+F_{\mathrm{Bfr}}^{\tau}(E)-\operatorname{Diss}_{\mathrm{Ver}}(E)-\operatorname{Diss}_{\mathrm{Hor}}(E)
$$

In this case, the work of the pressure forces and KE advection are expressed by the equation

$$
\operatorname{Adv}(P+E)=\left(u\left(g \zeta+E+P^{\prime}\right)\right)_{x}+\left(v\left(g \zeta+E+P^{\prime}\right)\right)_{y}+\left(w\left(g \zeta+E+P^{\prime}\right)\right)_{z} .
$$

The work of buoyancy force, the energy inflow from the wind and its loss due to friction against the bottom, KE dissipation due to vertical and horizontal internal friction are expressed as follows, respectively:

$$
\begin{gathered}
B F W=g \rho w, \\
F_{\mathrm{Bfr}}^{\tau}(E)=v_{V}\left(u u_{z}+v v_{z}\right)_{z}, \\
\operatorname{Diss}_{\mathrm{Ver}}(E)=v_{V}\left(u_{z}^{2}+v_{z}^{2}\right), \\
\operatorname{Diss}_{\mathrm{Hor}}(E)=v_{H}\left(\left(\nabla^{2} u\right)^{2}+\left(\nabla^{2} v\right)^{2}\right) .
\end{gathered}
$$


Integration (1) by volume provides:

$$
\begin{aligned}
& <E_{t}>_{V}+<\operatorname{Adv}(E)>_{V}+<\operatorname{Adv}(P)>_{V}=<B F W>_{V}+<\tau \rightarrow E>_{S}- \\
& -<\operatorname{Diss}_{\text {Ver }}(E)>_{V}-<\operatorname{Diss}_{\mathrm{Hor}}(E)>_{V} .
\end{aligned}
$$

In equation (2), for the convenience of the analysis, the term $\langle\tau \rightarrow E\rangle s$, which describes the KE inflow from the wind action, is separated and the contribution from $F_{\mathrm{Bfr}}^{\tau}(E)$ due to the friction against the bottom is included to $<\operatorname{Diss}_{\text {Ver }}(E)>v$.

We assume that mesoscale quasi-geostrophic eddies are those the radii of which are greater than the baroclinic Rossby deformation radius $\left(R_{d}\right)$ and the Rossby number (Ro) for which is much less than unity [16]:

$$
\begin{gathered}
R_{d}=\frac{\sqrt{g H(\Delta \rho / \rho)}}{f}, \\
\operatorname{Ro}=\frac{U}{R f},
\end{gathered}
$$

where $g$ is a gravitational acceleration; $H$ is an upper layer depth; $\rho$ is a seawater density at the surface; $\Delta \rho$ is a seawater density variation with depth; $f$ is the Coriolis parameter; $U$ is an orbital velocity of eddy; $R$ is an eddy radius. Following the formula (3), for the Marmara Sea at the values of parameters $g=9.8 \mathrm{~m} / \mathrm{s}^{2}, H=25 \mathrm{~m}, \Delta \rho / \rho=10^{-2}, f=9.53 \cdot 10^{-5} 1 / \mathrm{s}$ we obtain that $R_{d}=17 \mathrm{~km}$.

Winter season. Averaging over the winter hydrological season (as for all seasons) of current velocity fields, wind force work, buoyancy, pressure, KE advection, horizontal dissipation, vertical dissipation in the upper layer (Fig. 2) was carried out according to the formula

$$
\varphi=\frac{1}{H} \int_{0}^{H} \varphi d z,
$$

where $H \leq 20 \mathrm{~m}$.

A mesoscale anticyclone (Fig. 2, a) with a diameter of about $38 \mathrm{~km}$ and Ro $=0.017$ was formed in the northwestern part of the basin in the upper layer during the movement of waters from the Bosphorus to the Dardanelles. In the northern and northeastern parts of the sea, a system of two anticyclones with circulation radii of $10 \mathrm{~km}(\mathrm{Ro}=0.042)$ and $8 \mathrm{~km}(\mathrm{Ro}=0.053)$, respectively, exists. In the southern part of the sea, the movement of waters with cyclonic vorticity prevails. The radii of the gyres are 20 and $12 \mathrm{~km}$ (Rossby numbers are 0.021 and 0.041, respectively). Comparison of Fig. 2, $a$ and 2, $b$ allows us to conclude about their correspondence, which indicates the predominant effect of wind action on the formation of eddies. 

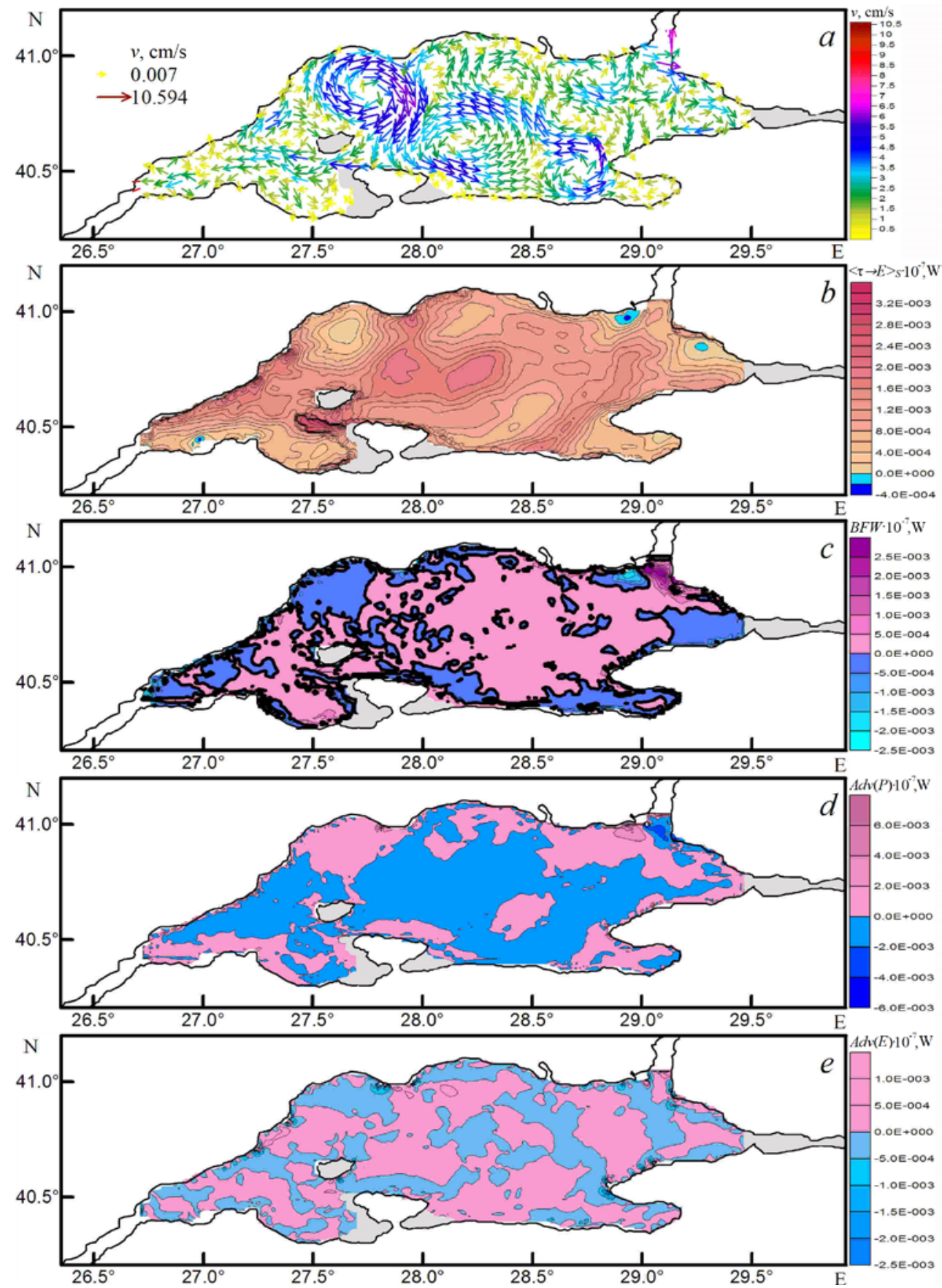

F i g. 2. Maps of the current velocity (vectors) ( $a$ ), wind force (b), buoyancy $(c)$, pressure $(d)$, kinetic energy advection $(e)$, horizontal dissipation $(f)$ and vertical dissipation $(g)$ (isolines) average fields in the upper 20-meter water layer of the Marmara Sea during the winter hydrological season 


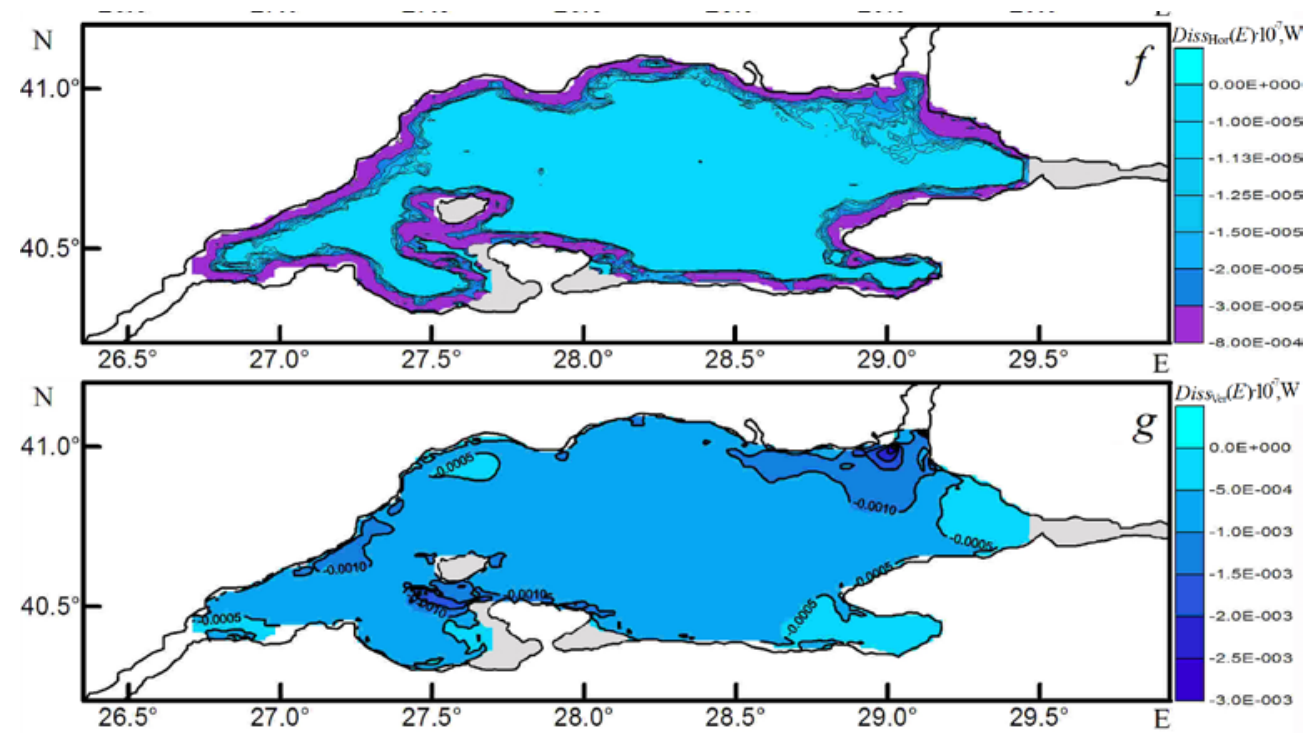

An important energy characteristic is the work of the buoyancy force [9], which provides an exchange between kinetic and available potential energy. On the map of the current velocity distribution (Fig. 2, a), in the vicinity of the entrance of water inflow from the Bosporus and Dardanelles straits, the cyclones with the centers at the points with $29.1^{\circ} \mathrm{E}, 40.7^{\circ} \mathrm{N} ; 28.8^{\circ} \mathrm{E}, 40.9^{\circ} \mathrm{N}$ and $26.9^{\circ} \mathrm{E}, 40.4^{\circ} \mathrm{N}$ coordinates and a circulation radius from 3 to $3.5 \mathrm{~km}$ are located. For these gyres, the Rossby numbers are $0.12 ; 0.09$ and 0.10 , respectively.

In Fig. 2, $c$ it can be seen that in the coastal areas corresponding to the location of cyclones, a negative buoyancy force work is observed (here and below, on the presented maps, the thick isoline corresponds to a zero value and separates positive and negative values). Large vertical gradients in the density field in these sea areas, caused by the inflow of waters of different density, indicate at an increase in the available potential energy reserve in these eddies and, thus, about their baroclinic structure.

In Fig. 2, $d$ a map of the pressure force work distribution for the winter season, on which the areas of positive contribution to the KE budget are highlighted in pink, is given. In the cyclonic circulation area this work is negative, in the area of the anticyclone it is positive. This indicates at its contribution to the KE variation rate in these eddies. In the coastal part of the sea, the pressure forces work is positive. Thus, the formation of eddies along the basin periphery is accompanied by the replenishment of KE due to the work of pressure forces. Apparently, this is due to the combined effect of baroclinicity and bottom topography [17, 18]. The influence of the advection on the budget of the KE in space (Fig. 2,e) is of an irregular nature and is several orders of magnitude less than the work of the pressure force. The extrema in its distribution correspond to the zones of flow PHYSICAL OCEANOGRAPHY VOL. 28 ISS. 5 (2021) 
running on the coastline inhomogeneity (Cape Bozburun, Cape Fanerbakhche, Cape Ferner, Cape Kodzhaburun in Fig. 1).

The map of horizontal dissipation distribution (Fig. 2, f) demonstrates an increase in dissipation along the periphery of the region, which is natural due to the conditions of adhesion of normal velocity component. The KE variation rate due to vertical friction is more complex (Fig. 2, $g$ ). Its extreme values are observed in the area of the Bosphorus and Marmara Island. These features correspond to the structure of the wind field; this suggests that contribution of mixing processes in this zone is predominant.

Spring season. In spring, an extensive anticyclonic gyre in the Marmara Sea upper layer (Fig. 3, a) with the maximum velocities up to $13.02 \mathrm{~cm} / \mathrm{s}$ and $R$ equal to $38 \mathrm{~km}(\mathrm{Ro}=0.028<<1)$ was formed. Eddies with smaller horizontal dimensions are located between the anticyclone and the coast. In the near-Bosporus part of the basin centered at a point with $29.00^{\circ} \mathrm{E}, 40.75^{\circ} \mathrm{N}$ coordinates an anticyclone with $\mathrm{R}=15 \mathrm{~km}$ and $\mathrm{Ro}=0.032$ was formed. At the points with $26.91^{\circ} \mathrm{E}, 40.40^{\circ} \mathrm{N}$; $27.40^{\circ} \mathrm{E}, 40.35^{\circ} \mathrm{N}$ and $28.85^{\circ} \mathrm{E}, 40.91^{\circ} \mathrm{N}$ coordinates the centers of cyclones, the radii of which are within the range from 4 to $6 \mathrm{~km}$, are located.
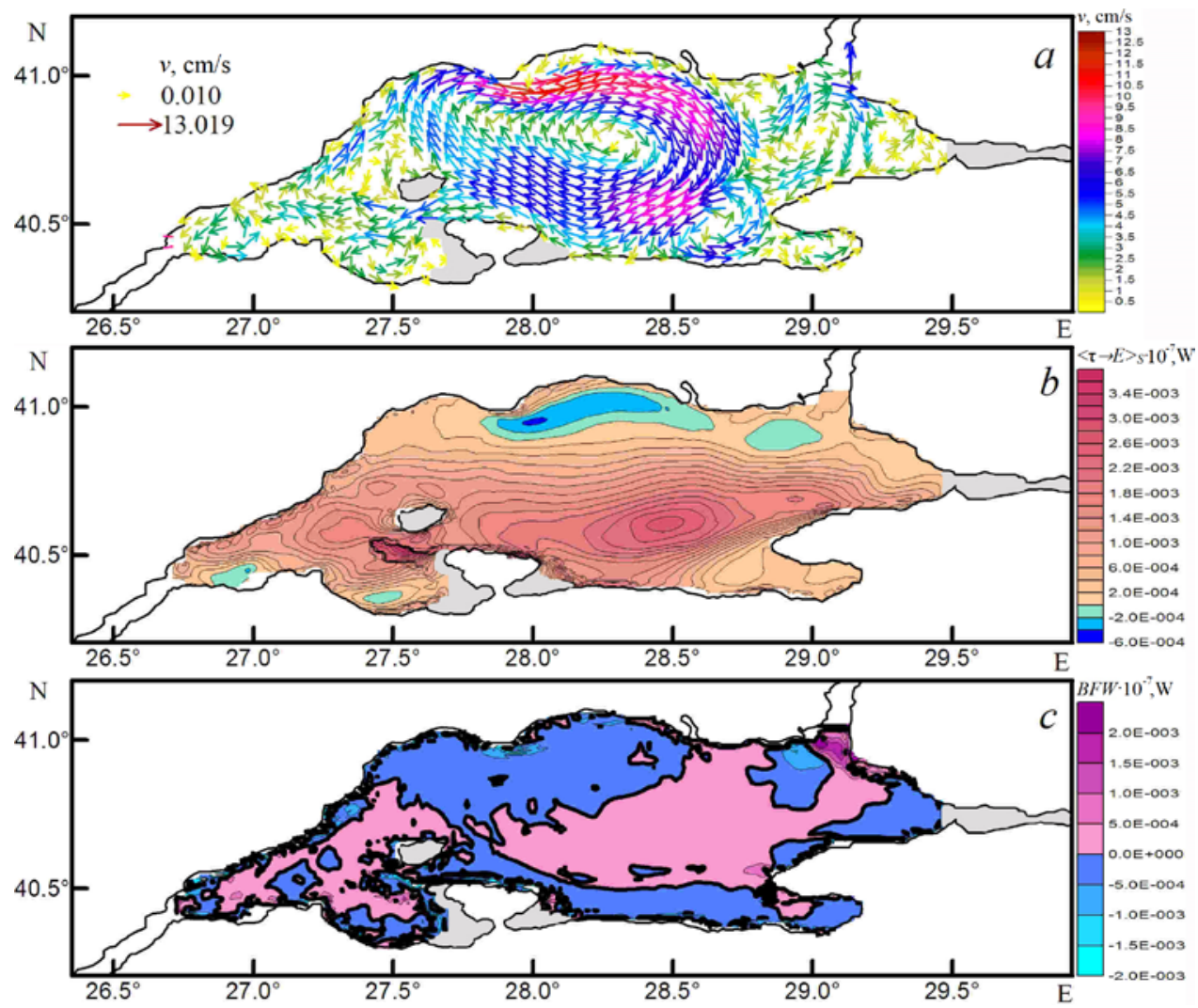

F i g. 3. Maps of the current velocity (vectors) ( $a$ ), wind force (b), buoyancy (c), pressure $(d)$, kinetic energy advection $(e)$, horizontal dissipation $(f)$ and vertical dissipation $(g)$ (isolines) average fields in the upper 20-meter water layer of the Marmara Sea during the spring hydrological season 
Continuation of Fig. 3

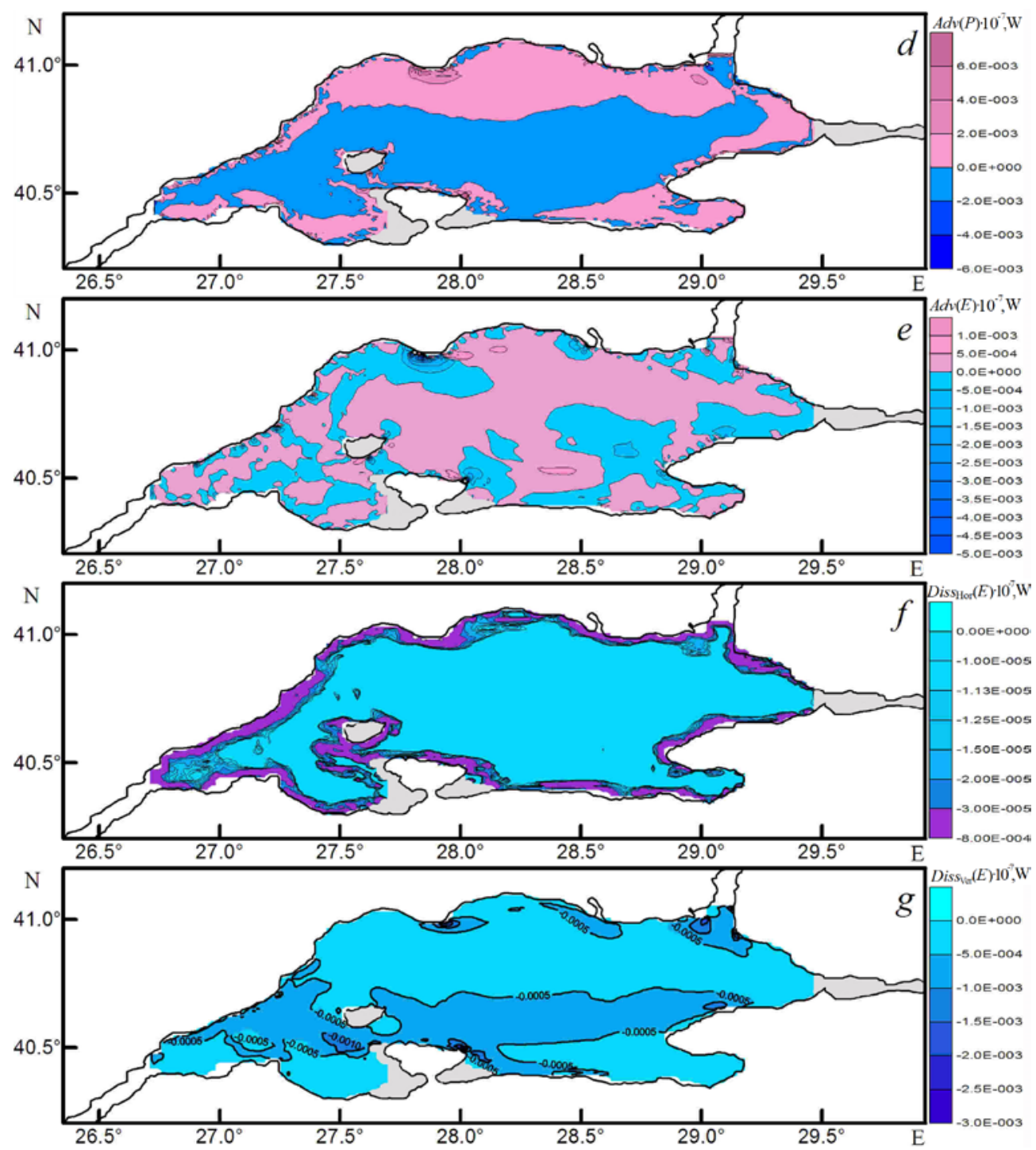

If for the central anticyclone the wind is the predominant factor of its formation (Fig. 3, b), then for cyclonic eddies its work is negative, which indicates the prevailing influence of other forces on their formation. Indeed, the buoyancy force work in these areas has local negative extrema (Fig. 3, c); therefore, the available potential energy serves as a reservoir for maintaining the intensity of cyclonic eddies, which is indirect evidence of the influence of baroclinic instability on the coastal circulation.

As in the winter season, the pressure force work in the sea coastal area has a positive value (Fig. 3, d), therefore it increases the eddy energy. KE advection is still of an irregular alternating character (Fig. 3, e) on irregularities of the coastal orography in the vicinity of the Fanerbahce, Baba, Ferner, Korjaburun capes and at 
the eastern edge of the Bandirma Peninsula (Fig. 1), where areas of extreme values are observed. As a result of the coastal currents strengthening, the extremes have increased, which can have a significant local effect in the energy balance.

The KE change rate due to horizontal and vertical dissipation in the spring season (Fig. 3, $f, g$ ) qualitatively corresponds to the winter period. There are quantitative differences in the magnitude of vertical dissipation, which are possibly associated with the warming up of surface waters and, therefore, with more stable vertical stratification.

Summer season. In summer period, as a result wind strengthening, the orbital velocity of the central anticyclonic gyre increased several times and reached $\sim 29 \mathrm{~cm} / \mathrm{s}$ (Fig. $4 a, b$ ). Smaller cyclonic eddies are still observed; an anticyclone located in the northwestern region merged with the central eddy, what influenced its power. The role of the buoyancy force work, which qualitatively corresponds to the spring season, increased, wherein its absolute values along the basin periphery increased (Fig. 4, c). Apparently, due to this, the eddies have become more regular. As well as for the spring season, the work of the pressure force is positive in almost the entire coastal area (Fig. 4, d) and therefore increases the KE of dynamic structures in these areas. The role of KE advection has increased (Fig. 4, e). The KE advection field has a more regular structure, different from the structure of the pressure force work field. The role of advection in the local KE increase in the area eastwards of Marmara Island and in the KE decrease in the zones of coastal inhomogeneities effect on coastal currents has significantly increased. The loss of energy due to horizontal dissipation in the regions of local extrema increased by about two times, which indicates the strengthening of coastal currents (Fig. 4, f). At the same time, the energy loss due to vertical friction accelerated, as shown in Fig. 4, $g$.

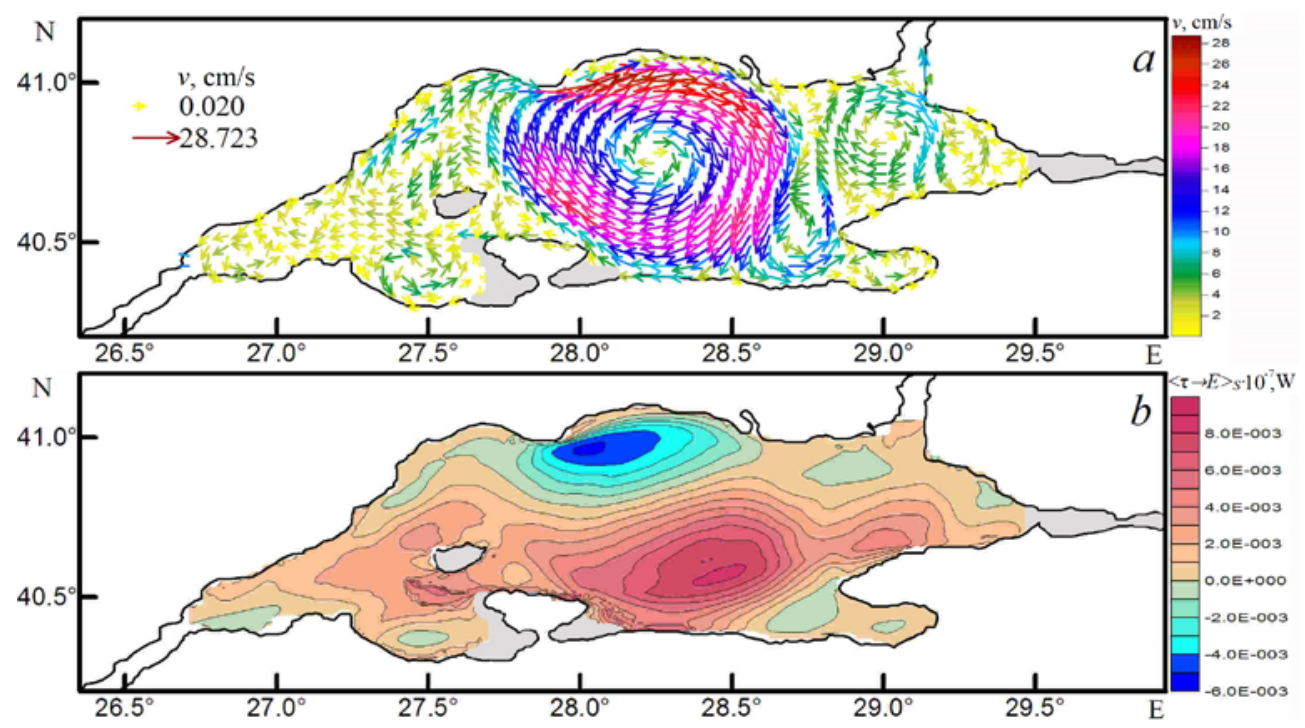

F i g. 4. Maps of the current velocity (vectors) $(a)$, wind force $(b)$, buoyancy $(c)$, pressure $(d)$, kinetic energy advection $(e)$, horizontal dissipation $(f)$ and vertical dissipation $(g)$ (isolines) average fields in the upper 20-meter water layer of the Marmara Sea during the summer hydrological season 
Continuation of Fig. 4
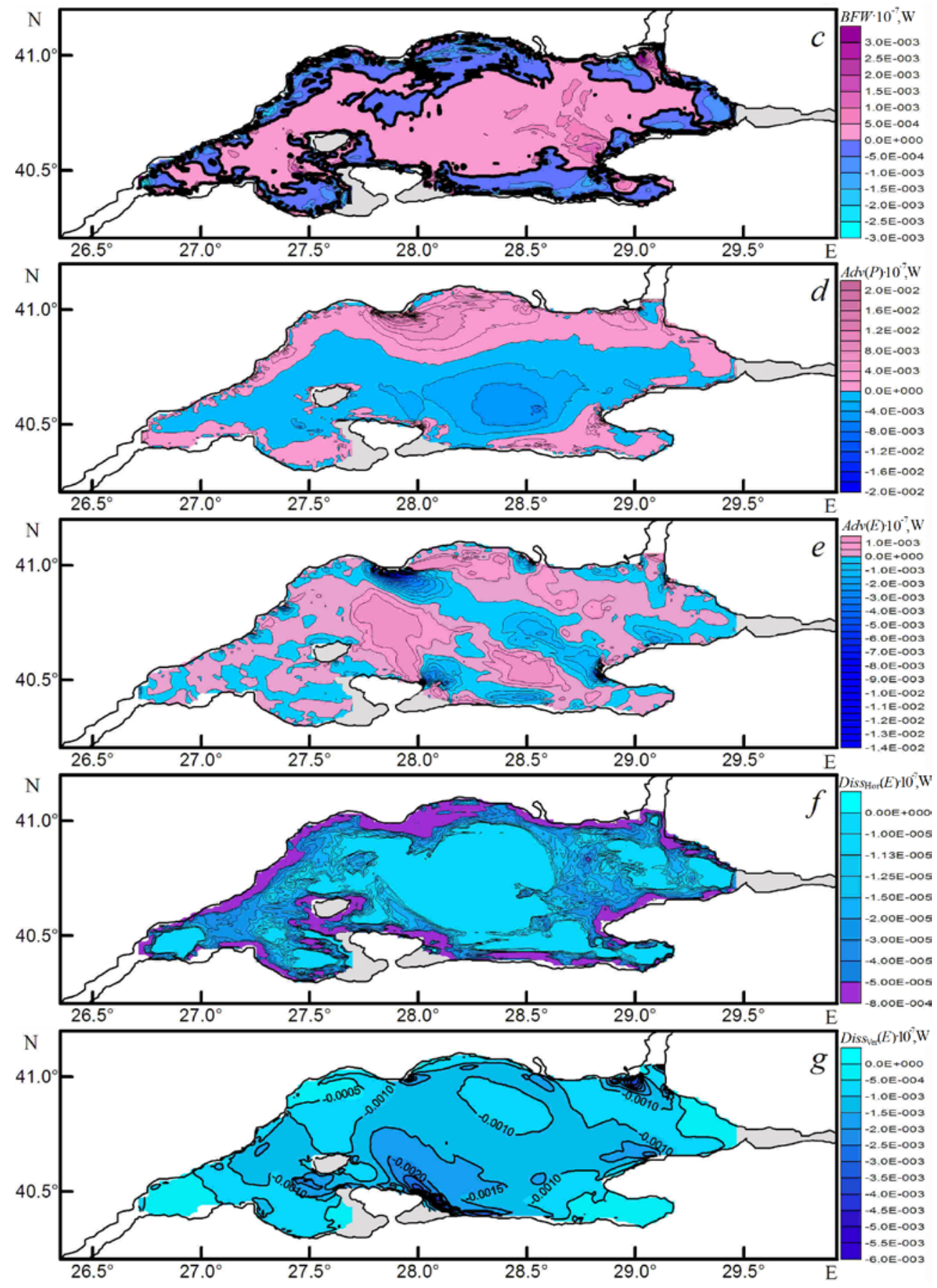

Autumn season. In the autumn period, the central anticyclone is significantly deformed, the main part of the basin is occupied by a chain of three large-scale eddies: anticyclone - cyclone - anticyclone. The area occupied by the anticyclone in PHYSICAL OCEANOGRAPHY VOL. 28 ISS. 5 (2021) 
the center of the basin has decreased, and the maximum current velocity in this case has decreased to $12.75 \mathrm{~cm} / \mathrm{s}$ (Fig. 5, a). At the same time, the cyclone area in the southeastern region of the sea increases, and its radius is now about $22 \mathrm{~km}$. The eddy structure of velocity field corresponds to the distribution of the wind force work (Fig. 5, b), wherein the number of areas of negative values in it increased (compared to the summer season). The existence of these areas indicates that in the autumn season the role of factors other than the work of the wind force increases.

As before, the spatial distribution of the Archimedean force work has a characteristic structure - positive values in the central part of the sea and negative values on its periphery (Fig. 5, c). Unlike previous seasons, the Archimedean force work is increasing. Apparently, the cooling of waters in the coastal strip by autumn leads to an increase in the heterogeneity of the density field vertically.

Unlike the summer season, in the structure of the field of the buoyancy force work an extremum is observed in the Izmit Bay area. Quantitative changes in the spatial distribution of the work of the forcies pressure and the KE advection (Fig. 5, $d, e$ ) are also observed. Compared to the summer period, the energy loss due to horizontal friction has decreased (Fig. 5, f). Qualitatively the structure of the friction field remains the same -the homogeneous field in the central region of the sea with local extrema along the periphery. In contrast to the summer period, in the distribution of energy loss due to dissipation along the vertical, one extremum remained in the area of the Bosphorus waters inflow (Fig. 5, g).

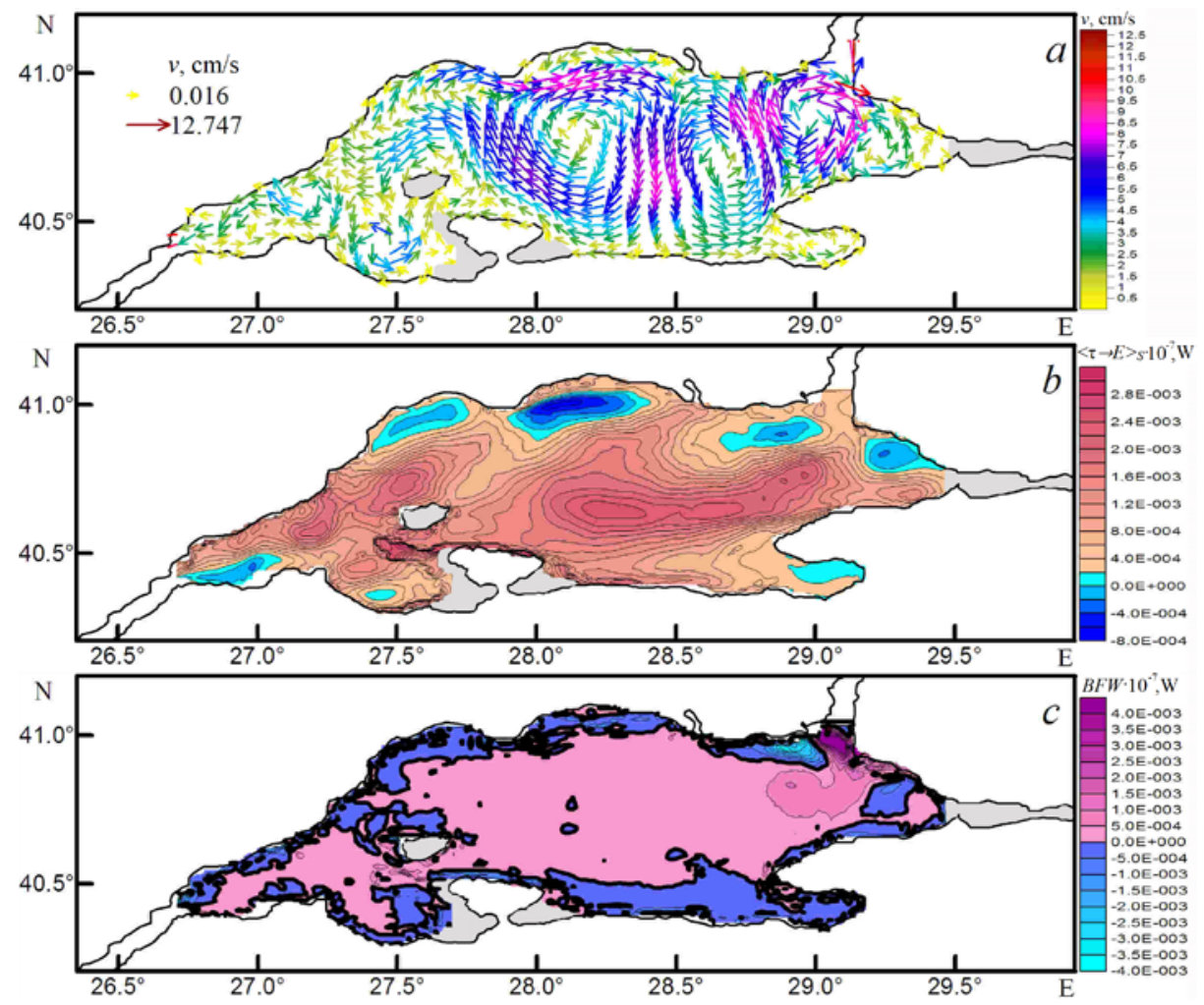

F i g. 5. Maps of the current velocity (vectors) ( $a$ ), wind force $(b)$, buoyancy $(c)$, pressure $(d)$, kinetic energy advection $(e)$, horizontal dissipation $(f)$ and vertical dissipation $(g)$ (isolines) average fields in the upper 20-meter water layer of the Marmara Sea during the autumn hydrological season 
Continuation of Fig. 5
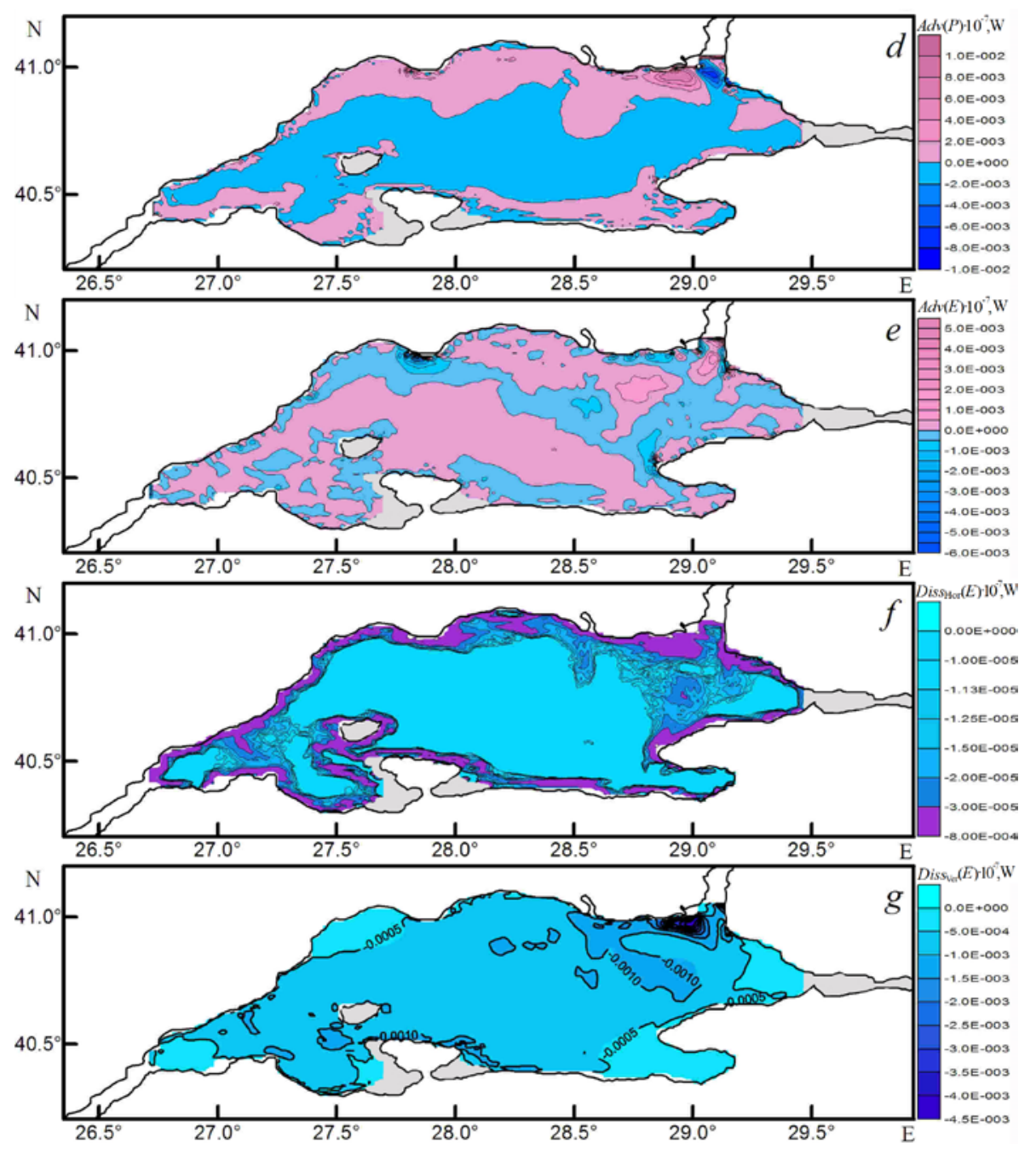

Conclusion

On the basis of the carried out numerical experiment on modeling the Marmara Sea circulation, the fields of hydrodynamic and energy characteristics averaged over the hydrological seasons of 2008 were obtained. The analysis average for the seasons spatial distributions of the current velocity fields and the components of the KE budget showed that eddies in the upper sea layer during the year are formed mainly by two mechanisms. In the central part of the sea, the generation of a large-scale anticyclone and its seasonal variability are mainly determined by the wind force work, and the formation and evolution of coastal cyclonic gyres are caused by the buoyancy force work.

The seasonal evolution of these mechanisms, which is most intense in the sea coastal area, is rather in their quantitative changes. The analysis of the energy characteristics showed that there are zones of the local extrema in the structure of 
the fields of the main forces (buoyancy, pressure and friction). Two of them are areas of water inflow from the Bosporus and Dardanelles straits, in which the processes of the eddy formations with horizontal scales from 3 to $15 \mathrm{~km}$ are observed. The greatest variability is observed in the Bosporus region, what is explained by the determining influence of the inflowing Black Sea waters on the seasonal nature of the Marmara Sea circulation. Other zones of extreme values are caused by inhomogeneities of the coastline, which leads to the formation of coastal eddies, the source of energy for which, along with shear instability, can be the available potential energy. The analysis of the buoyancy force work fields confirms that the alongshore zone is the source of the baroclinic instability.

1. Beşiktepe, T.S., Sur, H.I., Özsoy, E., Latif, M.A., Oguz, T. and Unluata, U., 1994. The Circulation and Hydrography of the Marmara Sea. Progress in Oceanography, 34(4), pp. 285-334. https://doi.org/10.1016/0079-6611(94)90018-3

2. Demyshev, S.G., Dovgaya, S.V. and Ivanov, V.A., 2012. Numerical Modeling of the Influence of Exchange through the Bosporus and Dardanelles Straits on the Hydrophysical Fields of the Marmara Sea. Izvestiya, Atmospheric and Oceanic Physics, 48(4), pp. 418-426. doi:10.1134/S0001433812040056

3. Chiggiato, J., Jarosz, E., Book, J.W., Dykes, J., Torrisi, L., Poulain, P.-M., Gerin, R., Horstmann, J. and Beşiktepe, Ş., 2012. Dynamics of the Circulation in the Sea of Marmara: Numerical Modeling Experiments and Observations from the Turkish Straits System Experiment. Ocean Dynamic, 62(1), pp. 139-159. doi:10.1007/s10236-011-0485-5

4. Zalesny, V.B., Gusev, A.V. and Fomin, V.V., 2016. Numerical Model of Nonhydrostatic Ocean Dynamics Based on Methods of Artificial Compressibility and Multicomponent Splitting. Oceanology, 56(6), pp. 876-887. https://doi.org/10.1134/S0001437016050167

5. Sannino, G., Sözer, A. and Ozsoy, E., 2017. A High-Resolution Modelling Study of the Turkish Straits System. Ocean Dynamic, 67(3), pp. 397-432. https://doi.org/10.1007/s10236-017-1039-2

6. Stanev, E., Grashorn, S. and Zhang, Y., 2017. Cascading Ocean Basins: Numerical Simulations of the Circulation and Interbasin Exchange in the Azov-Black-MarmaraMediterranean Seas System. Ocean Dynamic, 67(8), pp. 1003-1025. https://doi.org/10.1007/s10236-017-1071-2

7. Aydoğdu, A., Pinardi, N., Özsoy, E., Danabasoglu, G., Gürses, Ö. and Karspeck, A., 2018. Circulation of the Turkish Straits System under Interannual Atmospheric Forcing. Ocean Science, 14(5), pp. 999-1019. https://doi.org/10.5194/os-14-999-2018

8. Aydoğdu, A., Hoar, T.J., Vukicevic, T., Anderson, J.L., Pinardi, N., Karspeck, A., Hendricks, J., Collins, N., Macchia, F. and Özsoy, E., 2018. OSSE for a Sustainable Marine Observing Network in the Sea of Marmara. Nonlinear Processes in Geophysics, 25(3), pp. 537-551. https://doi.org/10.5194/npg-25-537-2018

9. Demyshev, S.G., 2004. Energy of the Black Sea Climatic Circulation. Part I: Discrete Equations of the Time Rate of Change of Kinetic and Potential Energy. Meteorology and Hydrology, (9), pp. 65-81 (in Russian).

10. Demyshev, S.G., Dovgaya, S.V. and Shokurov, M.V., 2016. Effect of Heat Flow, Precipitation and Evaporation on the Dynamics of the Marmara Sea Surface Water. Physical Oceanography, (3), pp. 3-13. doi:10.22449/1573-160X-2016-3-3-13

11. Demyshev, S.G., Dovgaya, S.V. and Shokurov, M.V., 2019. Energy Characteristics of the Marmara Sea Water Circulation in 2008. Physical Oceanography, 26(4), pp. 275-287. doi:10.22449/1573-160X-2019-4-275-287 
12. Jordà, G., von Schuckmann, K., Josey, S., Caniaux, G., García-Lafuente, J., Sammartino, S., Özsoy, E., Polcher, J., Notarstefano, G., Poulain, P.-M., Adloff, F., Salat, J., Naranjo, C., Schroeder, K., Chiggiato, J., Sannino, G. and Macías, D., 2017. The Mediterranean Sea Heat and Mass Budgets: Estimates, Uncertainties and Perspectives. Progress in Oceanography, 156, pp. 174-208. https://doi.org/10.1016/j.pocean.2017.07.001

13. Oguz, T., Özsoy, E., Latif, M.A., Sur, H.I. and Ünlüata, U., 1990. Modeling of Hydraulically Controlled Exchange Flow in the Bosphorus Strait. Journal of Physical Oceanography, 20(7), pp. 945-965. https://doi.org/10.1175/1520-0485(1990)020<0945:MOHCEF>2.0.CO;2

14. Zapevalov, A.S., 2005. Seasonal Variability of Vertical Temperature and Salinity Distribution in the Sea of Marmara. Meteorology and Hydrology, (2), pp. 78-84 (in Russian).

15. Beşiktepe, S.T., 2003. Density Currents in the Two-Layer Flow: an Example of Dardanelles Outflow. Oceanologica Acta, 26(3), pp. 243-253. https://doi.org/10.1016/S03991784(03)00015-X

16. Kamenkovich, V.M., Koshlyakov, M.N. and Monin, A.S., 1986. Synoptic Eddies in the Ocean. Amsterdam: Springer, 444 p. doi:10.1007/978-94-009-4502-9

17. Sarkisjan, A.S. and Ivanov, V.F., 1971. Joint Effect of Baroclinicity and Bottom Relief as an Important Factor in Dynamics of Sea Currents. Izvestiya, Atmospheric and Oceanic Physics, 7(2), pp. 173-188 (in Russian).

18. Sarkisyan, A.S., 2006. Forty Years of JEBAR - the Finding of the Joint Effect of Baroclinicity and Bottom Relief for the Modeling of Ocean Climatic Characteristics. Izvestiya. Atmospheric and Oceanic Physics, 42(5), pp. 534-554. https://doi.org/10.1134/S0001433806050021

About the authors:

Sergey G. Demyshev - Chief Research Associate, Wave Theory Department, FSBSI FSC MHI (2 Kapitanskaya Str., Sevastopol, 299011, Russian Federation), Dr.Sci. (Phys.-Math.), ORCID ID: 0000-0002-5405-2282, demyshev@gmail.ru

Svetlana V. Dovgaya - Junior Research Associate, Wave Theory Department, FSBSI FSC MHI (2 Kapitanskaya Str., Sevastopol, 299011, Russian Federation), ORCID ID: 0000-0003-3122-5053, dovgayasvetlana0309@yandex.ru

Contribution of the co-authors:

Sergey G. Demyshev - statement of the problem, analysis of the results

Svetlana V. Dovgaya - preparation of the model data, carrying out numerical experiments, analysis of the results, preparation of the graphic materials and the paper text

All the authors have read and approved the final manuscript.

The authors declare that they have no conflict of interest. 